\title{
Inhibition of capillary repair in proliferative glomerulonephritis results in persistent glomerular inflammation with glomerular sclerosis
}

\author{
Yukinari Masuda, Akira Shimizu, Mitue Kataoka, Takashi Arai, Arimi Ishikawa, Xuanyi Du, Sabine Kyoko Saito, \\ Kaoru Aki, Shinya Nagasaka, Akiko Mii, Emiko Fujita and Yuh Fukuda
}

The pathological process of glomerulonephritis $(\mathrm{GN})$ includes glomerular capillary damage, and vascular endothelial growth factor (VEGF) has an important role in glomerular capillary repair in GN. We examined the effect of inhibition of glomerular capillary repair after capillary injury in GN. Experimental Thy-1 GN was induced in rats that were divided into two groups: rats that received anti-VEGF neutralizing antibody $(50 \mu \mathrm{g}$ per $100 \mathrm{~g}$ body weight per day) and those treated with the vehicle from day 2 to day 9 . We assessed the renal function and histopathology serially until week 6 . Rats of the Thy-1 GN group showed diffuse glomerular mesangiolysis with ballooning destruction of the capillary network by day 3. $\mathrm{VEGF}_{164}$ protein levels increased in the damaged glomeruli during days 5 to 10 , and endothelial-cell proliferation increased with capillary repair in the vehicle-injected group. Proliferative GN resolved subsequently with decreased mesangial hypercellularity, and recovery of most of the glomeruli to the normal structure was evident by week 6 . In contrast, administration of anti-VEGF antibody significantly decreased endothelial-cell proliferation and capillary repair in glomeruli by week 2 . Thereafter, glomerular mesangial-cell proliferation and activation continued with persistent infiltration of macrophages. At week 6, segmental glomerular sclerosis developed with mesangial matrix accumulation and proteinuria. Deposition of type I collagen was also noted in sclerotic lesions. We conclude that impaired capillary repair was the underlying mechanism in the prolongation of glomerular inflammation in proliferative GN and in the development of glomerular sclerosis. Capillary repair has an important role in the recovery of glomerular damage and in the resolution of proliferative GN.

Laboratory Investigation (2010) 90, 1468-1481; doi:10.1038/labinvest.2010.130; published online 19 July 2010

KEYWORDS: anti-VEGF neutralizing antibody; capillary repair; endothelial cells; glomerulonephritis; inflammation; vascular endothelial growth factor

Injury of the glomerular capillary network is a common pathology in active glomerulonephritis (GN) and in other glomerular diseases, such as IgA nephropathy, lupus GN, necrotizing and crescentic GN, malignant hypertension, eclampsia, and thrombotic microangiopathy. ${ }^{1-5}$ Repair of the damaged tissue can usually occur after glomerular injury. ${ }^{2,6}$ Angiogenic capillary repair occurs during the period of recovery from glomerular damage associated with destruction of the glomerular capillary network. Vascular endothelial growth factor (VEGF), especially endogenous glomerular VEGF, has an important role in the glomerular capillary repair process in GN. ${ }^{7-10}$ After glomerular capillary injury, complete capillary repair of the damaged glomeruli facilitates full recovery of the glomerular architecture. ${ }^{11-13}$ However, there is little or no information on the effect of incomplete capillary repair in GN.

VEGF is an endothelial-specific growth factor known to promote endothelial-cell proliferation, differentiation, and survival, and to mediate angiogenesis, endotheliumdependent vasodilatation and microvascular hyperpermeability. ${ }^{14-16}$ Recently, VEGF-targeted therapies have been identified as promising therapeutic approaches in several diseases and malignant tumors. ${ }^{17-20}$ Three agents that target the VEGF pathway have shown clinical activity: bevacizumab, an anti-VEGF monoclonal antibody, and sorafenib and sunitinib, which are inhibitors of the small molecule

Department of Analytic Human Pathology, Nippon Medical School, Tokyo, Japan

Correspondence: A Shimizu, MD, PhD, Department of Analytic Human Pathology, Nippon Medical School, 1-1-5, Sendagi, Bunkyo-ku, Tokyo 113-8602 Japan.

E-mail: ashimizu@nms.ac.jp

Received 11 January 2010; revised 21 April 2010; accepted 28 April 2010 
VEGF-receptor tyrosine kinase. However, because VEGF is expressed in the kidneys, these agents have renal side effects, including proteinuria, hypertension, and thrombotic microangiopathy. ${ }^{21-24}$ Therefore, endogenous glomerular VEGF is considered to have a critical role not only in glomerular capillary repair but also in the maintenance of glomerular capillary endothelial cells in normal kidney homeostasis.

In the present study, we examined the effect of GN on glomerular capillary repair and used anti-VEGF neutralizing antibody to clarify the role of capillary repair in post-GN glomerular recovery. We also assessed the effects of inhibitors of capillary repair using a self-reversible proliferative GN model of Thy-1 GN in rats. In this GN model, proliferative GN subsides with glomerular capillary repair. ${ }^{11,12}$

\section{MATERIALS AND METHODS Thy-1 GN Model in Rats}

The animal experiments described in the present study were approved by the Ethics Review Committee for Animal Experimentation, Nippon Medical School. Male Wistar rats (Sankyo Laboratory, Tokyo, Japan) weighing $180 \mathrm{~g}$ were used for all experiments. Thy-1 GN was induced by the injection of monoclonal anti-Thy 1.1 antibody (OX7; Cedarlane Laboratories, Hornby, ON, Canada) at a dose of $60 \mu \mathrm{g} \operatorname{IgG}$ per $100 \mathrm{~g}$ body weight on day 0 . Rats were then treated with a neutralizing antibody against VEGF (rabbit anti-human VEGF antibody) dissolved in saline (Thy-GN with antiVEGF group) or control rabbit IgG (Millipore, Temecula, CA) in saline (Thy-1 GN group) using an intraperitoneal micro-osmotic pump (Alzet osmotic pump, model 2ML1; Alza, Mountain View, CA) starting at day 2 and ending at day 9 (1 week). The pumps were filled with anti-VEGF antibody ( $700 \mu \mathrm{g}$ per $2 \mathrm{ml}$ saline) and set to deliver the dose in 7 days (ie, $50 \mu$ g per $100 \mathrm{~g}$ body weight per day). This antibody is the same antibody which is used as VEGF-neutralizing antibody in the other laboratories. ${ }^{25,26}$ This antibody can inhibit the mitogenic activity of HUVEC in vitro, suppress the growth of tumor cells which produce VEGF in mice, and block endogenous and exogenous VEGF-mediated angiogenesis in rats. ${ }^{25,26}$ In the control group (Thy-1 GN group), rats were treated with equivalent dose of control rabbit $\operatorname{IgG}$ in saline instead of anti-VEGF rabbit IgG to exclude the effects of intravenous rabbit IgG, because intravenous immunoglobulin is known to have a number of immunosuppressive and anti-inflammatory effects on renal diseases. ${ }^{27,28}$ In each group, five rats were biopsied or killed on days 0,3 , and 7 , and in weeks 2,4 , and 6 after induction of Thy-1 GN. Five normal rats also received anti-VEGF antibody for 7 days (normal with anti-VEGF group). To estimate the renal function, urine and blood samples were collected for the measurement of urinary protein, plasma creatinine $(\mathrm{Cr})$, and blood urea nitrogen (BUN) using an autoanalyzer (SRL, Tokyo, Japan). These results were expressed as the mean \pm s.e.m., and compared statistically using the Student's $t$-test.

\section{Histopathological and Immunohistochemical Examination}

After removal of the kidney, renal tissues were fixed in $20 \%$ buffered formalin and embedded in paraffin for light microscopic examination. Tissues were stained with hematoxylin and eosin, periodic acid-Schiff, and periodic acid-methenamine silver (PAM) for histopathological examination.

For immunohistochemical examination, 20\% buffered formalin-fixed, paraffin-embedded tissue sections were used, and the specimens were stained using the standard avidinbiotin-peroxidase complex technique. The following antibodies were used for immunohistochemical examination: (a) polyclonal rabbit anti-rat thrombomodulin (TM) antibody $^{29}$ (kindly provided by Dr David Stern, Columbia University), which reacts with the endothelial-cell surface. This antibody has been used as a marker for endothelial cells; ${ }^{6,12}$ (b) monoclonal mouse anti-human $\alpha$-smooth muscle actin ( $\alpha \mathrm{SMA})$ antibody (1A4; Dako, Glostrup, Denmark), a marker of activated mesangial cells; (c) monoclonal mouse anti-proliferating cell nuclear antigen (PCNA) antibody (PC10; Dako), a marker of cell proliferation; (d) polyclonal goat anti-type IV collagen antibody (Southern Biotechnology Associates, Birmingham, AL), which is used for the evaluation of mesangial matrix accumulation and glomerular sclerosis; (e) polyclonal rabbit anti-VEGF antibody, ${ }^{30}$ which can detect VEGF-producing cells; (f) monoclonal mouse anti-flk-1 antibody (A-3; Santa Cruz Biotechnology, Santa Cruz, CA), which can detect VEGF receptor-expressing cells; (g) monoclonal mouse anti-rat ED1 antibody (BMA, Nagoya, Japan), which can detect infiltrating macrophages; (h) FITC-conjugated polyclonal goat antirabbit IgG antibody (Zymed, San Francisco, CA), which can detect the presence of injected rabbit anti-VEGF antibody.

For TM, type IV collagen, flk-1, and ED-1, tissue sections were incubated with $0.1 \%$ pepsin for $60 \mathrm{~min}, 0.1 \%$ pepsin for $30 \mathrm{~min}$ and $0.1 \%$ proteinase for $5 \mathrm{~min}, 0.1 \%$ proteinase for $5 \mathrm{~min}$, and $0.1 \%$ pepsin for $45 \mathrm{~min}$, respectively, before incubation with the primary antibody. For PCNA, sections were dewaxed first and then treated with microwaves for $10 \mathrm{~min}$ in $0.01 \mathrm{M}$ sodium citrate ( $\mathrm{pH}$ 6.0). Proliferating endothelial cells were identified after double immunohistochemistry staining with TM and PCNA, using the color modification method of 3,3-diaminobenzidine tetrahydrochloride (DAB) precipitation by nickel chloride, which changes the DAB color from brown to black. ${ }^{8,12}$ Sections were incubated with anti-rat TM antibody, a peroxidaseconjugated goat anti-rabbit IgG (Jackson Immunoresearch Laboratories, West Grove, PA), followed by DAB containing hydrogen peroxide $\left(\mathrm{H}_{2} \mathrm{O}_{2}\right)$. Sections were then incubated with PCNA followed by a peroxidase-conjugated goat antimouse IgG (BML), and $\mathrm{H}_{2} \mathrm{O}_{2}$, nickel chloride-containing DAB (DAB substrate kit for peroxidase, Vector Laboratories, Burlingame, CA). The expression of VEGF and the presence of exogenous anti-human VEGF antibody in glomeruli were 
examined using frozen samples. To detect the expression of VEGF, double immunohistochemical staining with VEGF and $\alpha \mathrm{SMA}$ was performed; $4-\mu \mathrm{m}$-thick frozen sections were stained with polyclonal rabbit anti-VEGF antibody followed by FITC-labeled goat anti-rabbit IgG antibody (Zymed). Sections were then incubated with anti- $\alpha$ SMA (mouse IgG2a) followed by Texas-red conjugated goat anti-mouse IgG2a (Biomeda, Foster City, CA). To determine the distribution of
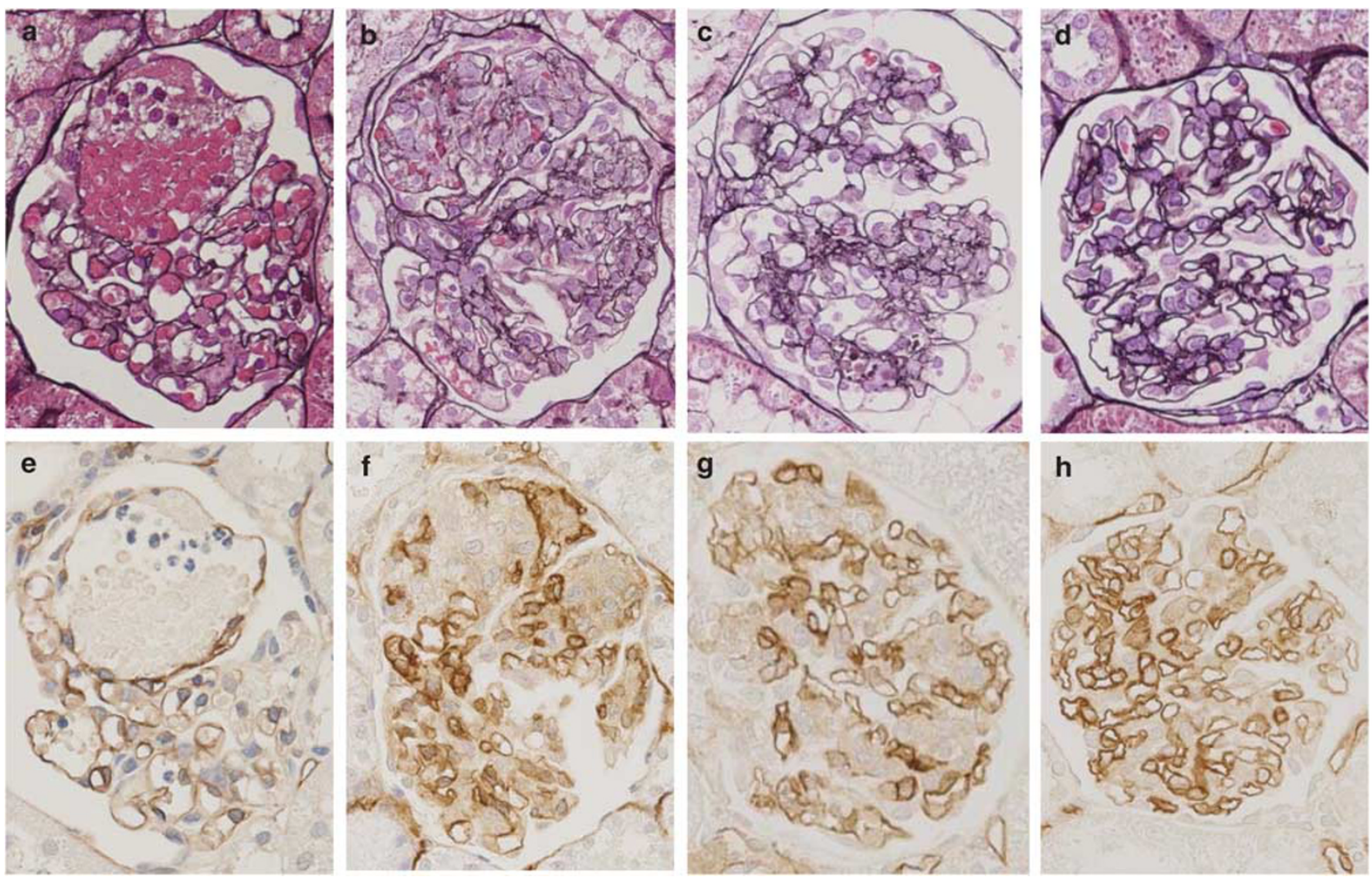

Figure 1 Resolution of proliferative GN with capillary regeneration in Thy-1 GN group $(\mathbf{a}-\mathbf{d}$ : PAM stain, $\times 600 ; \mathbf{e}-\mathbf{h}$ : TM stain, $\times 600)$. $(\mathbf{a}, \mathbf{e})$ Diffuse mesangial-cell lysis with the segmental destruction of capillary network "microaneurysmal ballooning" at 3 days after disease induction. (b, f) Proliferative GN at day 7 with regeneration of glomerular capillaries in proliferative lesions. $(\mathbf{c}, \mathbf{g})$ At week 2, glomerular proliferative lesions subsided with the development of glomerular capillary lumens. (d, h) By week 4, almost complete glomerular recovery to normal structure occurred, with the resolution of proliferative lesions and reconstruction of the capillary network.

Thy-1 GN

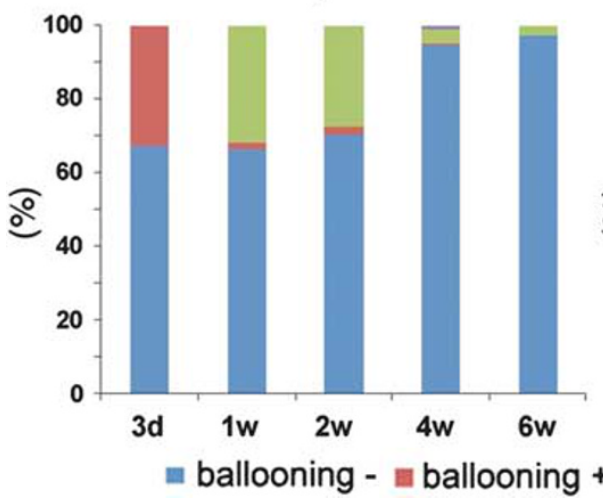

Thy-1 GN with anti-VEGF Ab

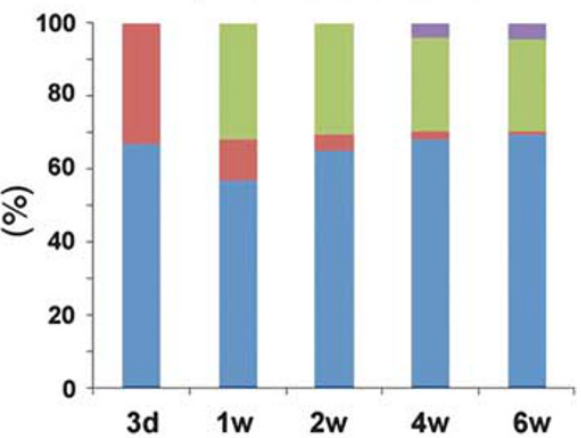

Figure 2 Percentages of glomeruli without ballooning lesions (ballooning-), with ballooning lesions (ballooning + ), proliferative lesions (proliferation + ), and sclerotic lesions (sclerosis + ) after ballooning during the course of Thy-1 GN in five rats of the Thy-1 GN group rats and five rats of the Thy-1 GN with anti-VEGF group. 
the injected rabbit anti-VEGF antibody, double immunohistochemical staining with VEGF and anti-type IV collagen (glomerular basement membrane) was performed; $4-\mu \mathrm{m}$ thick frozen sections were stained with FITC-labeled goat anti-rabbit IgG antibody (Zymed) followed by Texas-red conjugated anti-goat IgG (Biomeda). For all biopsies, negative controls were used, in which the primary antibody was substituted with equivalent concentrations of an irrelevant murine monoclonal antibody or normal rabbit IgG (DAKO). Subsequent analyses confirmed that all control sections were negative.

For electron microscopic examination, the renal tissues were fixed in $2.5 \%$ glutaraldehyde solution in phosphate buffer ( $\mathrm{pH}$ 7.4) and postfixed with $1 \%$ osmium tetroxide, dehydrated, and embedded in Epok 812. Ultrathin sections were stained with uranyl acetate and lead citrate or tannic acid, and then examined under an electron microscope (model H7100, Hitachi Corp, Tokyo, Japan).

\section{Isolation of Glomeruli and Western Blot Analysis for VEGF $_{164}$}

To examine the production of VEGF in glomeruli before and after disease induction, western blotting was performed using polyclonal rabbit anti-VEGF antibody (147; Santa Cruz Biotechnology). For this purpose, glomeruli were isolated as described previously, ${ }^{7,8,13}$ using a standard three-stage sieving method. The isolated glomeruli were homogenized in lysis buffer $(150 \mathrm{mmol} / \mathrm{l} \mathrm{NaCl}, 1 \%$ Nonidet P-40, $1 \%$ sodium deoxycholate, $0.1 \%$ SDS, $50 \mathrm{mmol} / \mathrm{l} \mathrm{NaF}, 10 \mu \mathrm{g} / \mathrm{ml}$ aprotinin, $10 \mu \mathrm{g} / \mathrm{ml}$ leupeptin, $1 \mathrm{mmol} / 1 \mathrm{Na}_{3} \mathrm{VO}_{4}, 1 \mathrm{mmol} / \mathrm{l}$ phenylmethylsulfonyl fluoride, and $20 \mathrm{mmol} / \mathrm{l}$ Tris- $\mathrm{HCl}, \mathrm{pH}$ 7.4). After centrifugation at $15000 \mathrm{~g}$ for $30 \mathrm{~min}$ at $4^{\circ} \mathrm{C}$, the supernatant was collected and used for analysis. Samples containing $10 \mu \mathrm{g}$ of protein per lane were separated on $10 \%$ acrylamide gel by SDS-PAGE. After electrophoresis, the separated proteins were transferred to a Hybond-P nitrocellulose membrane (Amersham Life Science, Buckinghamshire, UK) and incubated with anti-VEGF antibody (1:2000). The bound antibody was detected using peroxidase-conjugated anti-rabbit IgG antibody (1:1000; Jackson ImmunoResearch) with the enhanced chemiluminescence detection system (ECL western blotting detection regents, Amersham). Membranes were washed and then exposed to the film. To confirm equal loading of each protein, the membrane was stripped and reblotted with anti- $\beta$-actin antibody (Sigma, St Louis, MO).
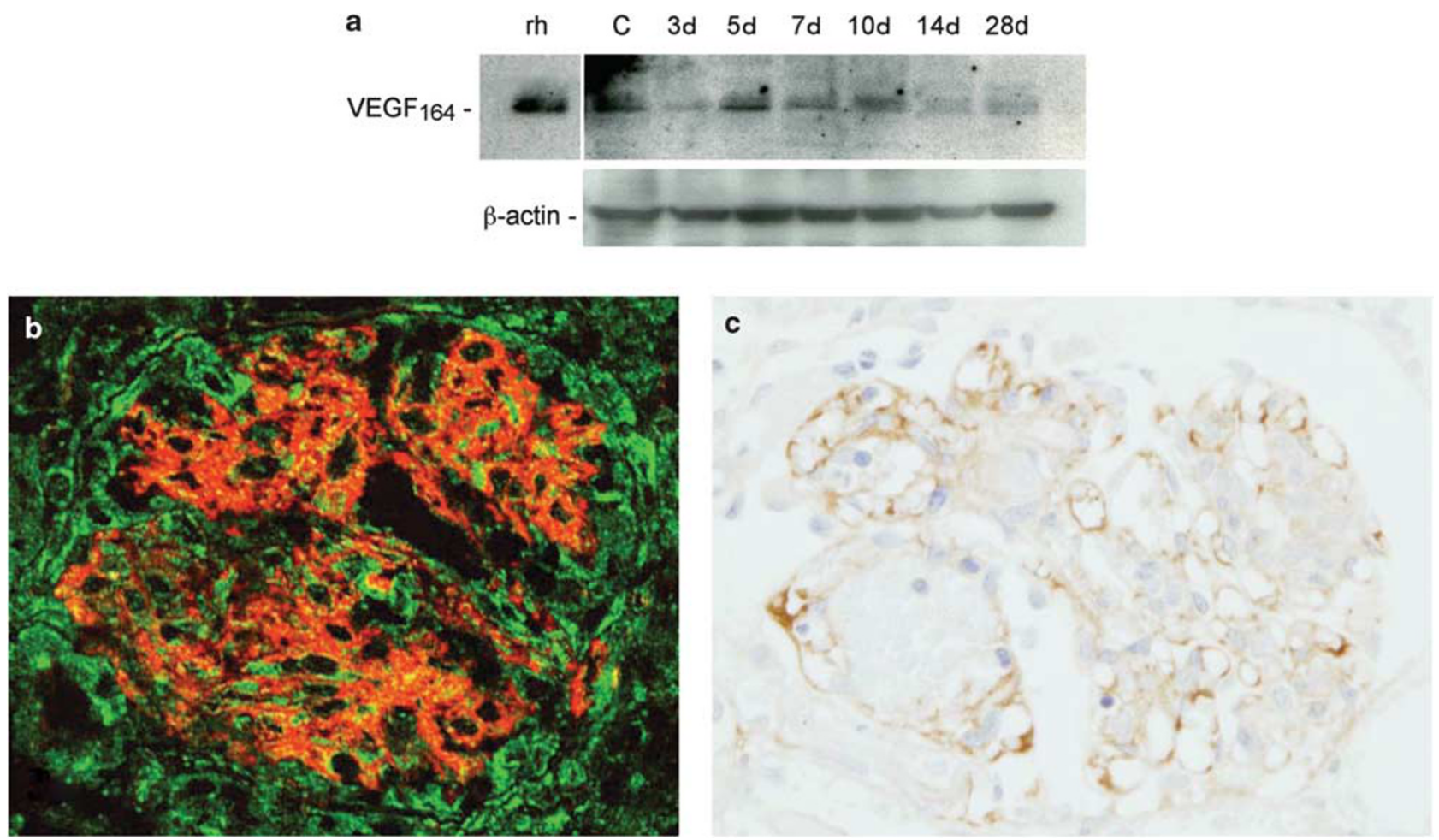

Figure 3 The protein levels of VEGF and the expression levels of VEGF and VEGFR-2 (flk-1) in the damaged glomeruli of rats with Thy-1 GN. (a) VEGF protein levels in the isolated glomeruli from control (C), and at 3 days (3d), 5 days (5d), 7 days (7d), 10 days (10d), 14 days (14d), and 28 days (28d) after GN induction. Note the upregulation of $\mathrm{VEGF}_{164}$ in the damaged glomeruli between days 5 and 10. (rh): bands of recombinant human VEGF 165 . Representative data of five other experiments with similar results are given. (b) Double immunofluorescence study of VEGF (green) and $\alpha$ SMA (red) showing VEGFexpressing glomerular epithelial cells (podocytes) and $\alpha \mathrm{SMA}^{+}$-activated mesangial cells in proliferative GN. (c) Proliferative glomeruli with VEGFR-2 (flk-1) expression on endothelial cells in the remaining glomerular capillaries (flk-1 stain, $\times 600$ ). 


\section{Quantification of Histopathological Findings}

In each kidney sample, $>40$ cross-sections of glomeruli were examined sequentially for the following parameters: (a) total number of endothelial cells, the mean number of $\mathrm{TM}^{+}$cells per glomerular cross-section; (b) proliferating endothelial cells, the mean number of both $\mathrm{PCNA}^{+}$and $\mathrm{TM}^{+}$cells per glomerular cross-section; (c) capillary repair, the mean number of glomerular capillary lumina surround by $\mathrm{TM}^{+}$ cells per glomerular cross-section; (d) infiltrating macrophages, the mean number of $\mathrm{CD}^{+} 8^{+}$cells per glomerular cross-section. In addition, for the evaluation of (e) activated mesangial-cell area and (f) sclerotic area in glomeruli, more than 40 cross-sections of glomeruli were graded semiquantitatively based on the specimens stained for $\alpha \mathrm{SMA}$ and type IV collagen, respectively, using the following grading system: ${ }^{7,31,32} 0=$ diffuse, very weak or absence of glomerular staining, and no localized increase in staining; $1+=$ up to $25 \%$ of the glomerular tuft showed focal increase in staining; $2+=25-50 \%$ of the glomerular tuft showed focal increase in staining; $3+=50-75 \%$ of the glomerular tuft showed focal increase in staining; $4+=\geq 75 \%$ of the glomerular tuft showed focal increase in staining. We also determined the frequencies of microaneurysmal ballooning lesions, proliferative lesions after ballooning (post-ballooning) lesions, and sclerotic lesions with post-ballooning lesions. For this purpose, 100 glomeruli in each animal were examined for glomeruli with and without ballooning lesions, proliferative lesions after ballooning lesions, and sclerotic lesions after ballooning lesions. The percentages of the glomeruli with each of these lesions were calculated on each day after Thy-1 GN induction in Thy-1 GN and Thy-1 GN with anti-VEGF groups. Glomerular cross-sections containing only a small portion of the glomerular tuft were excluded from the analysis. All histopathological evaluations were performed by investigators blinded to the treatment modality. These results were
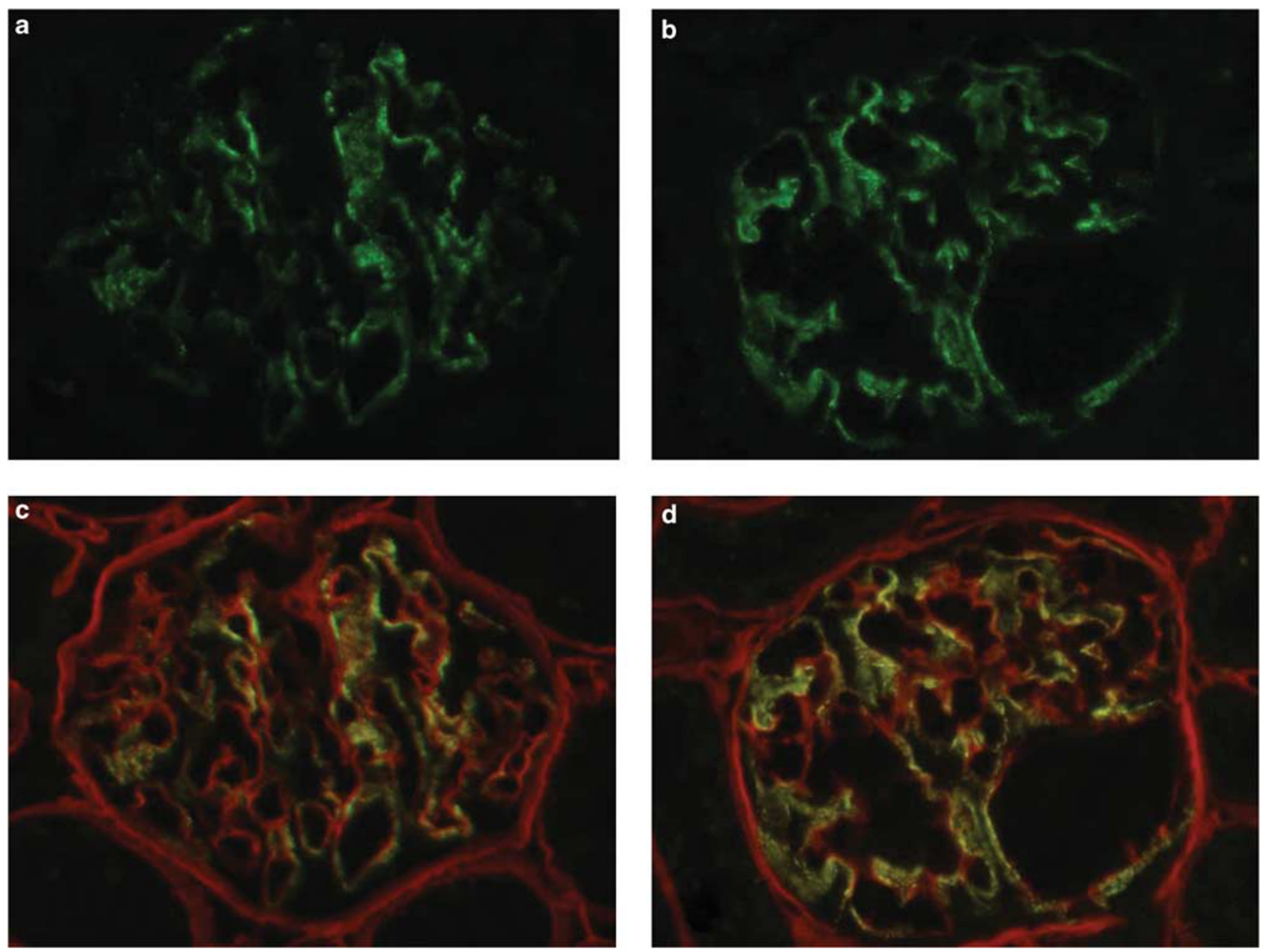

Figure 4 Distribution of the injected VEGF-neutralizing antibody in glomeruli. Immunofluorescence staining with rabbit lgG (injected anti-VEGF neutralizing antibody) (a, b) and double immunofluorescence staining with rabbit IgG (FITC) and type IV collagen (Texas-red) (c, $\mathbf{d}$ ) showed the presence of the injected anti-VEGF neutralizing antibody mainly along the capillary walls and focal mesangial areas in glomeruli of normal control rats (a, c) and Thy-1 GN with anti-VEGF group (b, d) at week 1 (5 days of continuous anti-VEGF antibody administration). 
expressed as the mean \pm s.e.m. and were compared statistically using the Student's $t$-test.

\section{RESULTS}

\section{Glomerular Capillary Network In Thy-1 GN}

Wistar rats developed Thy-1 GN characterized by diffuse mesangiolysis at 1 day after the injection of the antibody to Thy-1.1 antigen, which is present on mesangial cells. Failure of the capillary support function of mesangial cells resulted in the destruction of the capillary network and in the progression of the mesangiolytic lesions to segmental microaneurysmal ballooning (Figure 1). Segmental ballooning lesions were observed in about 30 to $40 \%$ of the glomeruli at day 3 (Figure 2). Glomerular endothelial cells disappeared in the ballooning lesions with destruction of glomerular capillary network (Figure 1). Thereafter, mesangial hypercellularity was noted at day 7 , with the development of mesangial proliferative GN. However, Thy-1 GN was transient, and massive mesangial-cell proliferation and mesangial-matrix expansion gradually subsided followed by the regeneration of glomerular capillary network (Figures 1 and 2). At week 2, the glomerular hypercellularity and amount of matrix component diminished, and glomerular capillary network developed with increased capillary lumina. Subsequently, most of the damaged glomeruli recovered their normal structure by week 4 to 6 .

\section{VEGF Expression and Reaction of Injected Anti-VEGF Antibody in Glomeruli}

Before disease induction, VEGF was expressed mainly on podocytes in normal glomeruli (data not shown). Although VEGF $_{164}$ protein level decreased in isolated glomeruli at day 3 , probably in association with podocyte injury after mesangiolysis, it increased between day 5 and 10 (Figure 3). Thereafter, VEGF ${ }_{164}$ protein levels decreased by week 4 . At day 7, VEGF was expressed on podocytes and activated mesangial cells (Figure 3). VEGF receptor 2 (flk-1) was expressed on glomerular endothelial cells in the damaged capillaries (Figure 3 ).

We also examined the effect of inhibition of VEGFinduced angiogenic capillary repair on the course of Thy-1 GN. In these experiments, anti-VEGF antibody was injected into normal rats (normal with anti-VEGF group) or rats with Thy-1GN (Thy-1 GN with anti-VEGF group) from day 2 to
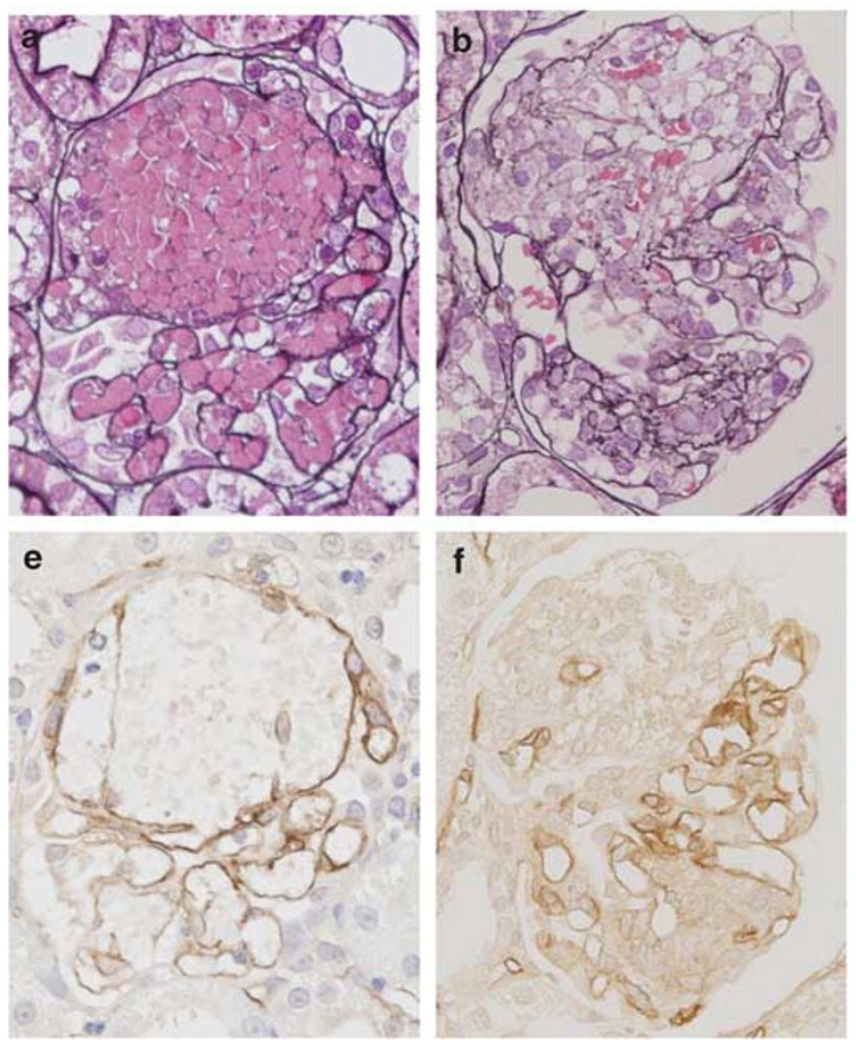
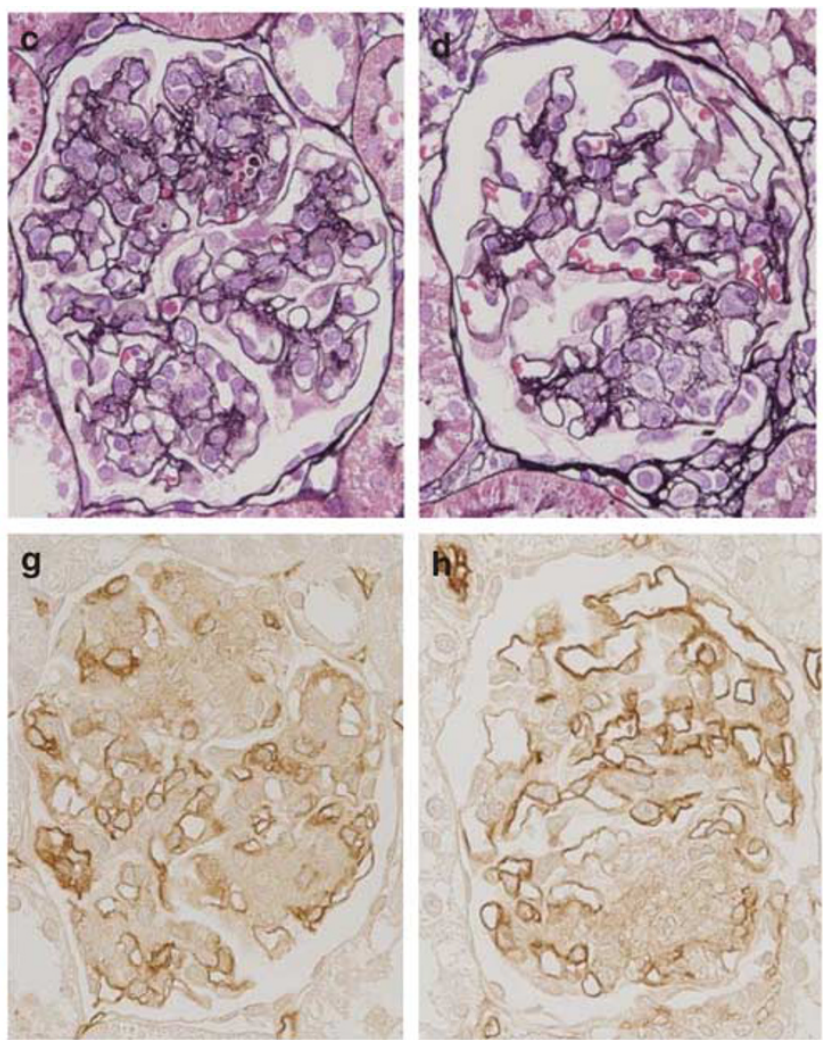

Figure 5 Glomerular inflammation in rats of the Thy-1 GN/anti-VEGF group (a-d: PAM stain, $\times 600 ; \mathbf{e}-\mathbf{h}$ : TM stain, $\times 600$ ). (a, e) At day 3 (1 day of anti-VEGF antibody administration), note the development of diffuse mesangial-cell lysis and segmental capillary aneurysmal ballooning, similar to the rats of the Thy-1 GN group. (b, f) Administration of anti-VEGF neutralizing antibody inhibited glomerular capillary regeneration, and ballooning lesions without proliferative lesions were still seen in some glomeruli at week 1. (c, g) Repair of glomerular capillary network in impaired ballooning lesions at week 2. Segmental mesangial hypercellularity was still present with mesangial matrix accumulation at week 2 . (d, h) Segmental loss of glomerular capillary lumens was noted in segmental mesangial proliferative and sclerotic lesions at week 4. 
day 9 (7 days), at the time of upregulated VEGF expression in glomeruli. At day 7, the exogenous anti-VEGF antibody was deposited mainly along the glomerular capillaries in the glomeruli of normal rats injected with anti-VEGF and Thy-1 injected with anti-VEGF (Figure 4).

\section{Effects of Anti-VEGF Antibody in Thy-1 GN}

In rats with Thy-1 GN and treated with anti-VEGF, diffuse mesangiolysis and segmental capillary microaneurysmal ballooning were noted in about $40 \%$ of the glomeruli at day 3 , followed by mesangial hypercellularity at week 1 , similar to the rats of the Thy-1 GN group (Figures 2 and 5). However, administration of anti-VEGF neutralizing antibody inhibited glomerular capillary regeneration, and ballooning lesions without proliferative lesions remained in about $10 \%$ of the glomeruli at week 1 . Segmental mesangial hypercellularity was present at week 2 to week 4 , with incomplete recovery of the glomerular capillary network. At week 6, segmental proliferative and sclerotic lesions were still noted in about $30 \%$ of the glomeruli, including sclerotic lesions in $5 \%$ of the glomeruli, with a few glomerular capillary lumens (Figures 2 and 6). Irregular dilatation of glomerular capillary lumens was also evident, as indicated by incomplete capillary repair. In parallel with the histopathological evidence of chronic glomerular damage, proteinuria was developed in rats with Thy-1 GN/anti-VEGF (Figure 7), although no significant differences were noted in serum $\mathrm{Cr}$ and BUN levels between rats of Thy-1 GN and Thy-1 GN/anti-VEGF groups (data not shown).

We also examined the effects of treatment with anti-VEGF antibody on the evolution of Thy-1 GN. First, we assessed the effects of anti-VEGF antibody on the injury of glomerular endothelial cells in normal rats and in rats with Thy-1 GN. In normal rats treated with anti-VEGF antibody continuously for 7 days, the fenestrae of endothelial cells were well preserved and we did not detect any morphological alterations
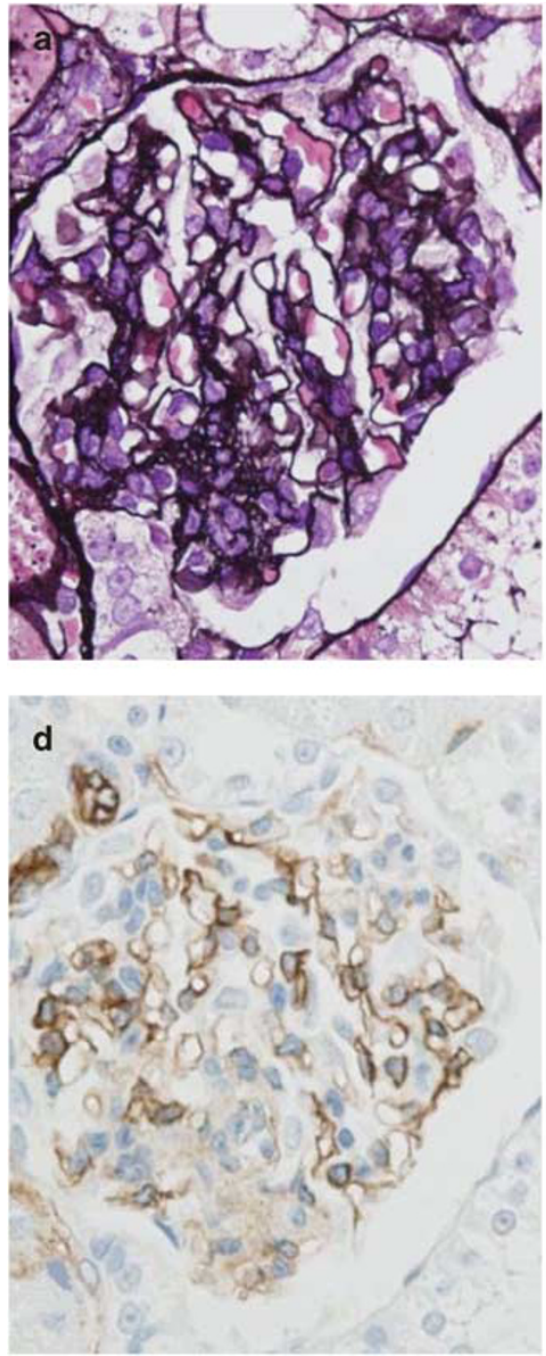
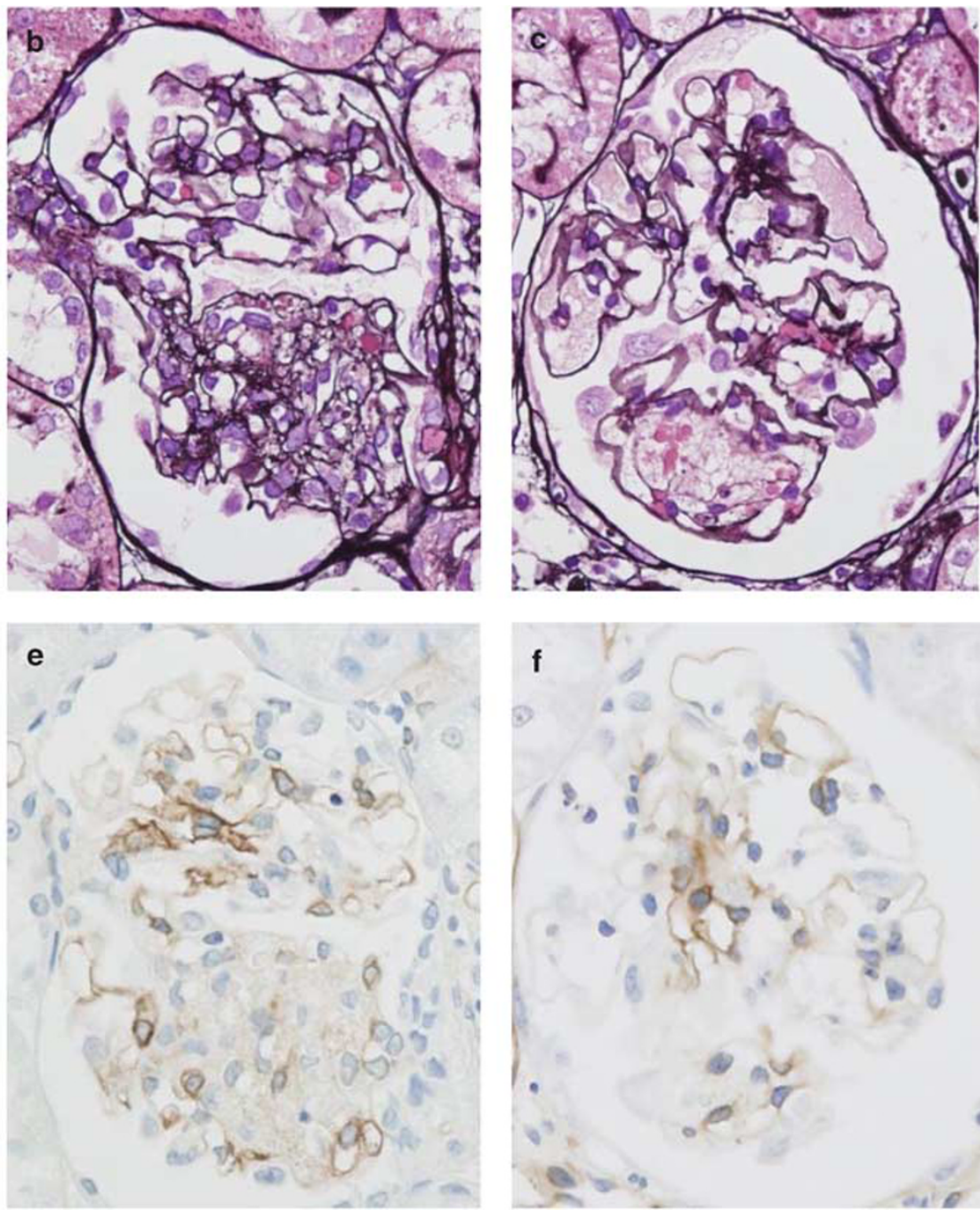

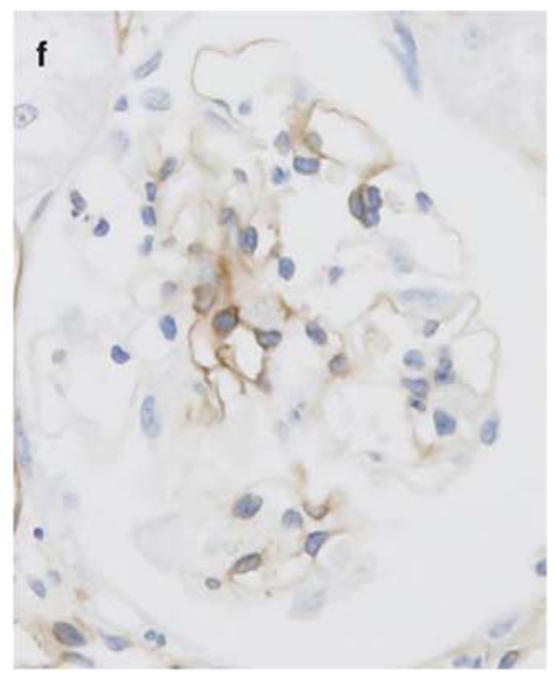

Figure 6 Changes in glomeruli of rats in the Thy-1 GN/anti-VEGF group at week 6 (a-c: PAM stain, $\times 600 ; \mathbf{d}-\mathbf{f}$ : TM stain, $\times 600$ ). Note the loss of glomerular capillary network in segmental proliferative and sclerotic lesions. Also note the irregular dilatation of glomerular capillary lumen in mesangiolytic lesions. 
in glomeruli (Figure 8). Rats of the Thy-1 GN/anti-VEGF group showed no enhancement of endothelial-cell injury at day 3 ( 1 day after commencement of anti-VEGF antibody), on the basis of the number of glomerular endothelial cells and capillary lumens per glomerular cross-section, and the rate of microaneurysmal ballooning lesions was not significantly different between Thy-1 GN and Thy-1 GN/antiVEGF groups (Figure 2). In our study, administration of anti-VEGF antibody for at least 1 day did not mediate the endothelial-cell injury in the diseased glomeruli. Second, we assessed the effect of anti-VEGF antibody on the inhibition of endothelial-cell proliferation and glomerular capillary repair in Thy-1 GN. Just after the endothelial-cell injury, endothelial cells started proliferating at day 3 , and proliferation continued at week 1 during the increase in protein levels of glomerular VEGF in the Thy-1 GN group (Figures 9 and 10). The proliferating endothelial cells increased significantly in number at day 3 and week 1 which was followed by a rapid recovery in the number of total $\mathrm{TM}^{+}$glomerular endothelial

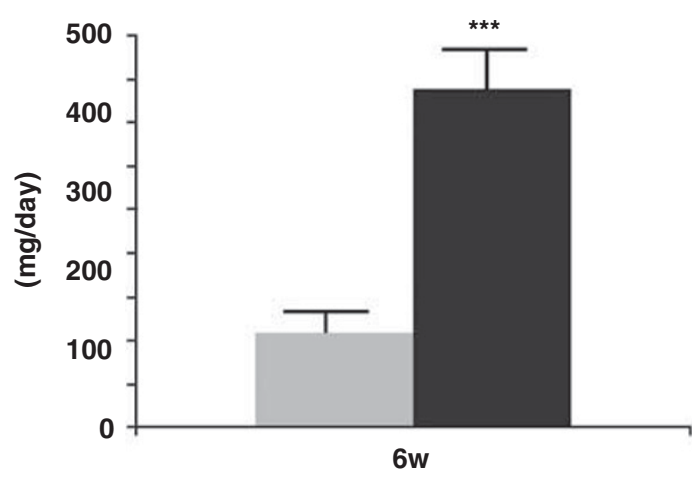

= Thy-1 GN $=$ Thy-1 GN +anti-VEGF

Figure 7 Urinary protein levels in Thy-1 GN and Thy-1 GN/anti-VEGF groups at week 6 . Values are mean \pm s.e.m. of five rats in each group. ${ }_{* * * * *} P<0.001$ compared with Thy-1 GN group. cells by week 2 (Figure 10). Thereafter, the glomerular capillary network redeveloped by week 6 resulting in an increased number of glomerular capillary lumina per glomerular cross-section (Figure 10). Electron microscopy showed immature capillaries at sites where ballooning had occurred at week 2. They matured to almost normal glomerular capillary structures (Figure 11). On the other hand, administration of anti-VEGF antibody from day 2 to day 9 resulted in the disappearance of the majority of proliferating endothelial cells $\left(\mathrm{PCNA}^{+} / \mathrm{TM}^{+}\right)$from the ballooning lesions at day 7 (Figures 9 and 10). In parallel with the low level of glomerular endothelial-cell proliferation, incomplete capillary regeneration was noted in the damaged glomeruli. At weeks 2 to 4, capillary regeneration and proliferation of glomerular endothelial cells was not prominent in segmental proliferative lesions. The number of glomerular capillary endothelial cells and glomerular capillary lumens per glomerular cross-section gradually increased, but did not reach their normal levels by week 6 . Electron microscopic study showed a few capillaries in post-ballooning lesions at week 2 (Figure 11). At week 6, segmental sclerotic lesions were noted with tannic acid-stained collagen fibers in the sclerotic lesions. These results indicate that VEGF-neutralizing antibody inhibits the endothelial-cell proliferation and capillary repair of damaged glomeruli in Thy-1 GN.

Finally, we examined the effects of anti-VEGF antibody on glomerular inflammation in Thy-1 GN (Figures 12 and 13). In both Thy-1 GN and Thy-1 GN/anti-VEGF groups, numerous $\alpha \mathrm{SMA}^{+}$-activated mesangial cells were found in the proliferative lesions obtained from the early phase of GN. Subsequently, mesangial hypercellularity was noted at week 1 and week 2. Anti-VEGF antibody was injected from day 2 to day 9. At day 3 and week 1, during the injection of antiVEGF antibody, the area of $\alpha \mathrm{SMA}^{+}$-activated mesangial cells, the amount of extracellular matrix (type IV collagen), and the number of infiltrating $\mathrm{CD}^{+} 8^{+}$macrophages in glomeruli were not different between Thy-1 GN and Thy-1
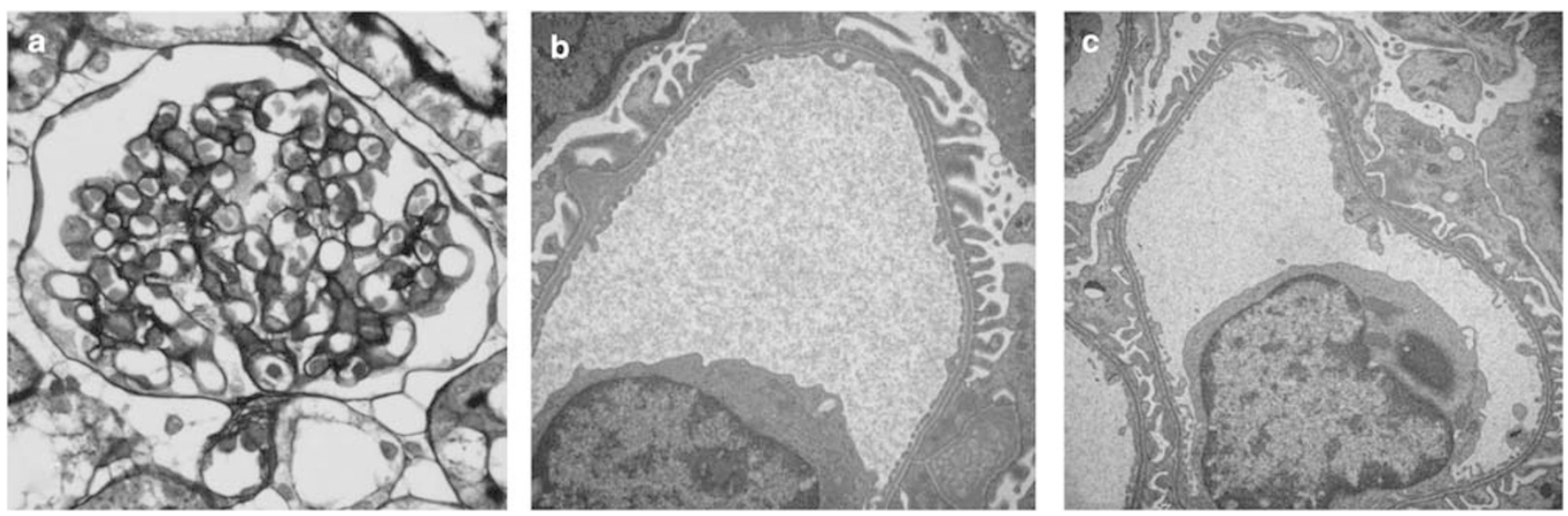

Figure 8 No development of glomerular endothelial-cell injury in normal rats after 7 days administration of anti-VEGF antibody. (a) No glomerular alteration was seen in normal rats at day 9, just after 7 days administration of anti-VEGF antibody (PAM stain, $\times 600$ ). The fenestra of glomerular endothelial cells was well preserved in the glomeruli at day $9(\mathbf{b} ; \times 15000)$ and at 6 weeks (about 7 weeks after 7 days administration of anti-VEGF antibody) $(\mathbf{c} ; \times 15000)$. 

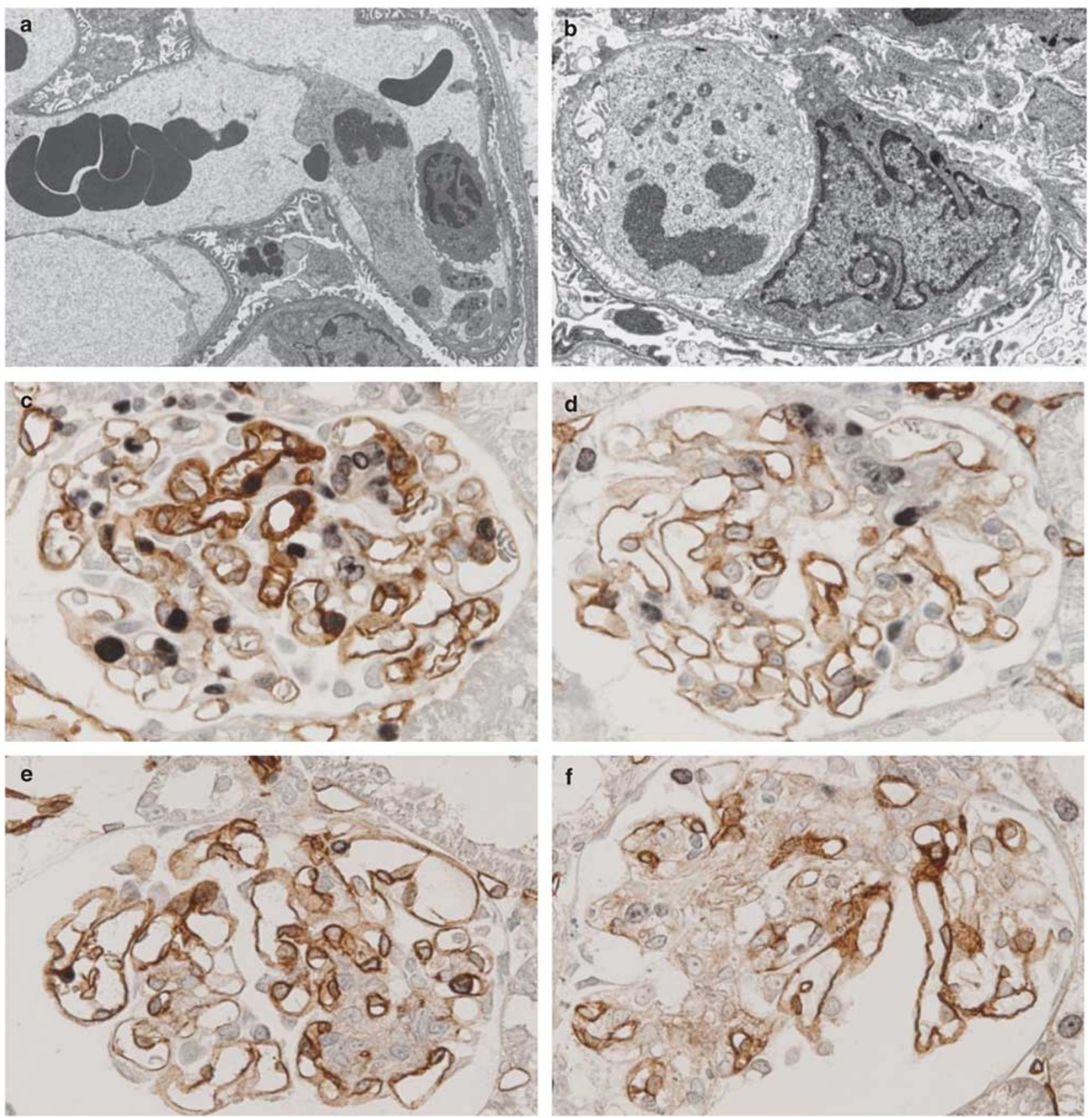

Figure 9 Proliferation of glomerular endothelial cells in Thy-1 GN and Thy-1 GN/anti-VEGF groups. Mitosis of glomerular endothelial cells was evident in the damaged glomeruli at day $3(\mathbf{a}, \times 2500)$ and day $7(\mathbf{b}, \times 5000)$ in rats of the Thy-1 GN group. Double immunohistochemistry with TM (brown) and PCNA (black) (c-f) showed that both $\mathrm{TM}^{+}$- and PCNA ${ }^{+}$-proliferating endothelial cells were prominent in rats of the Thy-1 GN group at day 3 (c). In contrast, they were not prominent in rats of Thy-1 GN/anti-VEGF group at day 3 (d), indicating the inhibition of endothelial-cell proliferation by anti-VEGF antibody. Only a few $\mathrm{TM}^{+}$- and PCNA ${ }^{+}$-proliferating endothelial cells were noted in rats of the Thy- 1 GN group at week 2 with almost complete recovery of glomerular capillary network (e). Similarly, only a few $\mathrm{TM}^{+}$- and PCNA ${ }^{+}$-proliferating endothelial cells were noted in rats of the Thy-1 GN/anti-VEGF group at week 2, although the recovery of capillary glomerular network was incomplete (f).

GN/anti-VEGF groups. In addition, at week 2, ie, at day 5 after the cessation of anti-VEGF antibody therapy, activation and extracellular matrix accumulation of mesangial cells were also not different between the two groups. These findings indicate that anti-VEGF antibody does not directly cause the activation and matrix accumulation of mesangial cells, and macrophage infiltration in disease glomeruli in vivo.

However, in Thy-1 GN, anti-VEGF antibody altered glomerular inflammation by inhibiting the capillary repair. In thy-1 GN, mesangial hypercellularity was reversible and 


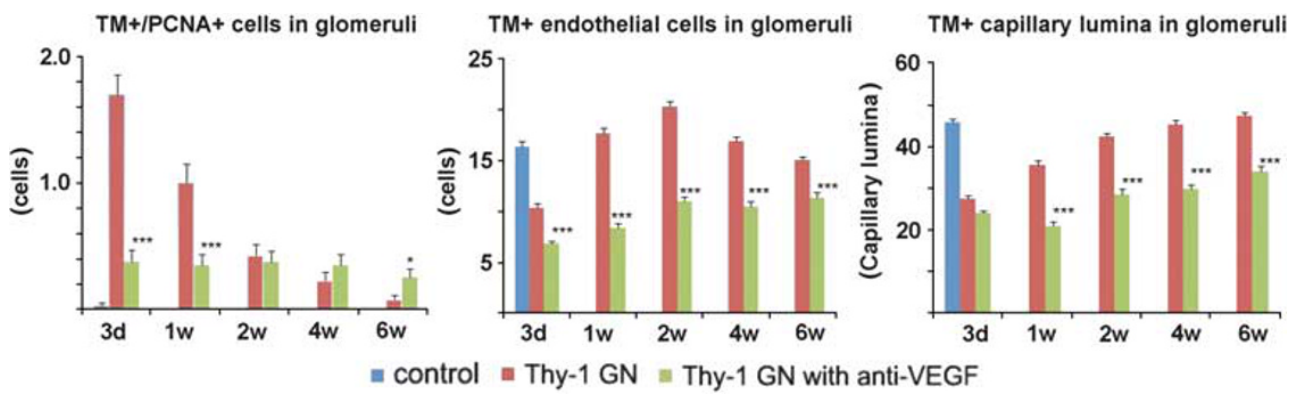

Figure 10 Numbers of $\mathrm{PCNA}^{+}$- and $\mathrm{TM}^{+}$-proliferating endothelial cells (a), total $\mathrm{TM}^{+}$endothelial cells $(\mathbf{b})$, and TM ${ }^{+}$glomerular capillary lumens (c) per glomerular cross-section, during the entire experiment. Values are mean \pm s.e.m. of five rats in each group. ${ }^{*} P<0.05,{ }^{* *} P<0.001$, compared with the Thy- $1 \mathrm{GN}$ group.
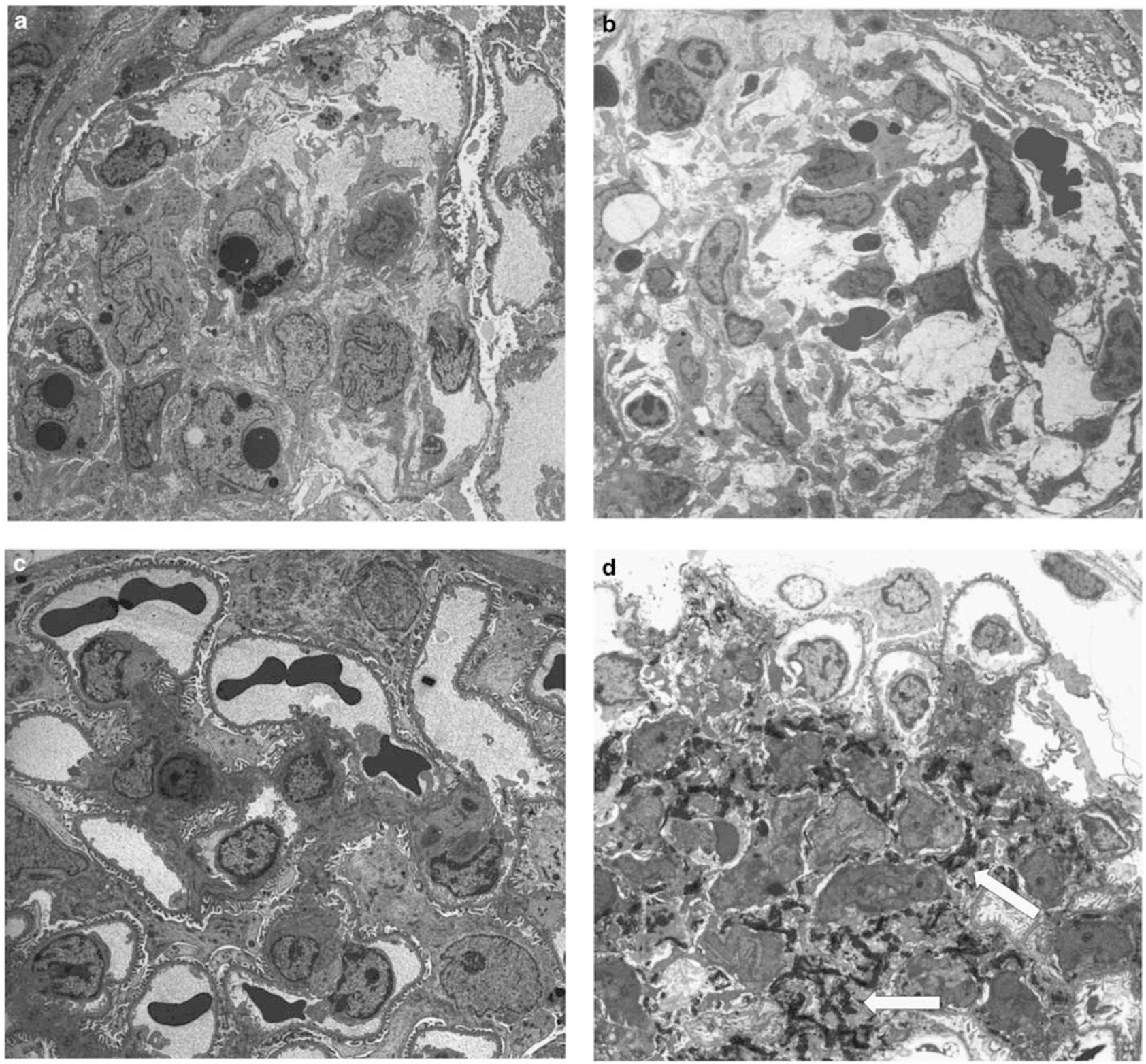

Figure 11 Glomerular capillary regeneration after destruction of capillary network in rats of Thy-1 GN (a, c) and Thy-1 GN/anti-VEGF (b, d) groups at week 2 $(\mathbf{a}, \mathbf{b}: \times 1000)$ and week $6(\mathbf{c}, \mathbf{d}$ : Tannic acid stain, $\times 1000)$. Many immature capillary lumens were observed in the glomeruli of rats of the Thy-1 GN group at week 2, and glomerular capillary network developed to their normal structure by week 6 . In contrast, in rats of the Thy-1 GN/anti-VEGF group, nti-VEGF antibody inhibited glomerular capillary repair in ballooning lesions, and a few capillaries were seen in the damaged glomeruli at week 2. Note the segmental sclerotic lesions with a few glomerular capillary lumens, accumulation of mesangial matrix and deposition of tannic acid stain ${ }^{+}$collagen fibers (arrow). 
correlated with the development of glomerular capillary network; mesangial-cell hypercellularity and matrix expansion gradually subsided in the damaged glomeruli during the recovery phase. By week 6 , healing of the majority of damaged glomeruli was noted, with the attainment of near-normal structure and no extention of $\alpha \mathrm{SMA}^{+}$or type IV collagen ${ }^{+}$areas (Figure 13). In contrast, in the Thy-1 GN/anti-VEGF group, segmental mesangial hypercellularity with $\alpha \mathrm{SMA}^{+}$-activated mesangial cells and $\mathrm{CD}^{+} 8^{+}$macrophage infiltration were persistently seen in the damaged glomeruli at weeks 4 and 6. Persistent glomerular inflammation with the accumulation of mesangial matrix (type IV collagen) was associated with the development of segmental glomerular sclerosis. These results indicate that inhibition of glomerular capillary repair after glomerular capillary injury in GN mediates the prolongation of glomerular inflammation and the development of glomerular sclerosis.

\section{DISCUSSION}

Administration of anti-VEGF neutralizing antibody inhibited the proliferation of glomerular endothelial cells and regeneration of capillaries in the damaged glomeruli in Thy-1 GN. Inhibition of glomerular capillary repair with anti-VEGF antibody resulted in persistent proliferation and activation of mesangial cells together with the infiltration of glomerular macrophages and subsequent development of segmental glomerular sclerosis with proteinuria. In sclerotic lesions, few glomerular capillaries were present with mesangial matrix accumulation and type I collagen deposition. We conclude that incomplete capillary repair mediates the prolongation of
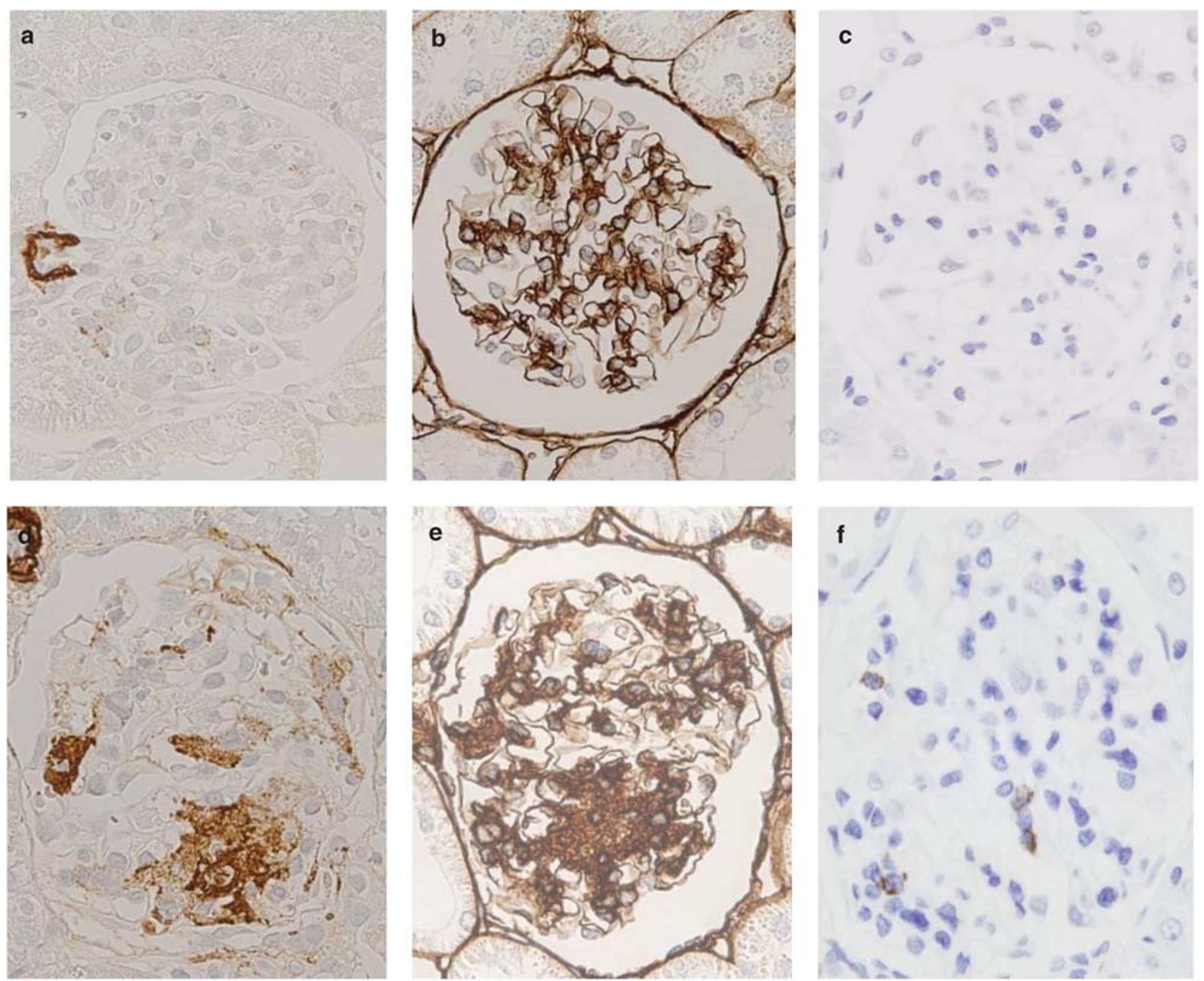

Figure 12 Activation of mesangial cells, glomerular sclerosis, and infiltration of macrophages in rats of the Thy-1 GN (a, c, e) and Thy-1 GN/anti-VEGF $(\mathbf{b}, \mathbf{d}, \mathbf{f})$ groups at week 6 . Glomerular damage in rats of the Thy-1 GN group at week 6 showed complete recovery to the original structure with no $\alpha \mathrm{SMA}^{+}$-activated mesangial cells, minimal type IV collagen ${ }^{+}$sclerotic lesions, and minimal ED1 ${ }^{+}$macrophage infiltration. In contrast, rats of the Thy-1 GN/anti-VEGF group at week 6 showed persistent segmental mesangial hypercellularity in glomeruli with $\alpha \mathrm{SMA}^{+}$-activated mesangial cells, IV collagen ${ }^{+}$sclerotic lesions, and infiltration of ED1 ${ }^{+}$macrophages. 


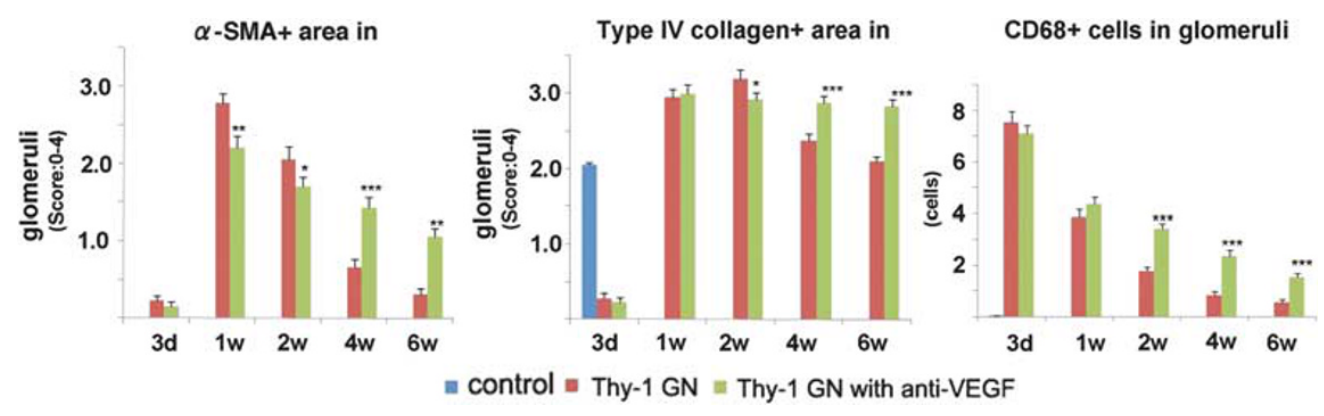

Figure 13 Scores of $\alpha \mathrm{SMA}^{+}$areas (a), type IV collagen ${ }^{+}$areas (b), and number of $\mathrm{CD}^{+} 8^{+}$macrophages (c) per glomerular cross-section in rats of the Thy-1 GN and Thy-1 GN/anti-VEGF groups. Values are mean \pm s.e.m. of five rats in each group. ${ }^{*} P<0.05,{ }^{* * P}<0.01,{ }^{* *} P<0.001$, compared with the Thy-1 GN group.

proliferative GN, which develops into segmental glomerular sclerosis. In other words, capillary repair has an important role in the recovery from glomerular injury as well as resolution of proliferative GN.

A study from another laboratory assessed the effects of blockade of endogenous VEGF in rat with Thy-1 GN, using VEGF $_{165}$ aptamer, an oligonucleotide-based VEGF $_{165}$ antagonist, and showed that the $\mathrm{VEGF}_{165}$ aptamer reduced glomerular endothelial regeneration and increased endothelial-cell death, resulting in the accumulation of glomerular microaneurysms in the early period of disease induction. ${ }^{7}$ In contrast, administration of the $\mathrm{VEGF}_{165}$ aptamer did not influence early leukocyte influx, and proliferation, activation, and matrix accumulation of mesangial cells. Our present study also showed that systemic injection of anti-VEGF neutralizing antibody inhibited glomerular endothelial-cell proliferation, decreased glomerular capillary regeneration, and suppressed glomerular capillary repair in the diseased glomeruli. In addition, anti-VEGF antibody did not directly affect the infiltration and activation of macrophages or matrix accumulation of mesangial cells. In our study, however, the frequency of ballooning lesions by day 3 was not significantly different between Thy-1 GN and Thy-1 GN/anti-VEGF groups. Differences between the results of the two studies may be because of the differences in molecules of the used antagonists, route of administration, or day of inhibition of VEGF activity. $^{7}$

Early glomerular endothelial injury is a feature of many human diseases, including preeclampsia, hemolytic uremic syndrome, lupus GN, most types of vasculitis, many forms of $\mathrm{GN}$, as well as renal transplant rejection. ${ }^{1,5,33}$ Glomerular endothelial damage also characterizes a variety of conditions associated with glomerular hypertension, hyperperfusion, and hyperfiltration. ${ }^{1-3}$ Several studies have shown that capillary repair after glomerular capillary destruction can lead to full recovery of the glomerular architecture. ${ }^{6,12}$ Repair of the glomerular capillary network, with endothelial-cell proliferation, in the damaged glomeruli is mediated through upregulated expression of VEGF and its receptor, VEGFR-2 (flk-1). In addition, systemic administration of VEGF can initiate the repair of glomerular capillaries in the damaged glomeruli on the basis of its angiogenic and vascular remodeling properties. ${ }^{7,8}$ In contrast, the present study indicated that inhibition of capillary repair in glomerular disease associated with capillary injury resulted in the development of glomerular sclerosis. Furthermore, impaired capillary regeneration in glomerular capillary injury mediated the prolongation of glomerular inflammation with mesangial-cell activation, extracellular matrix accumulation, and infiltration of macrophages. In other words, our results indicated that capillary repair is an important event in glomerular healing as well as in the resolution of proliferative GN.

In another part of the renal microvasculature, peritubular capillary (PTC) injury contributes to tubulointerstitial scarring and renal dysfunction during the development of chronic renal diseases. ${ }^{34-36}$ PTC disruption and regression with the development of tubulointerstitial scarring may be associated with a decrease in VEGF in tubular epithelial cells. $^{36,37}$ Moreover, recent reports show that systemic administration of VEGF can mediate PTC endothelial-cell proliferation and prevent the development of interstitial fibrosis and renal dysfunction. ${ }^{38,39}$ The maintenance of renal microvasculature including glomeruli and PTCs is therefore crucial to the suppression of disease progression in renal diseases, and capillary repair in GN could be used as a new therapeutic strategy for the development of novel agents against GN.

Recent reports have indicated that endogenous VEGF from podocytes has an important role in health and maintenance of the glomerular endothelium and the glomerular capillary network. $^{40}$ In the pathogenesis of eclampsia, anti-antiangiogenic factors, specifically soluble fms-related tyrosine kinase 1 (sflt-1), and soluble endoglin secreted by the placenta are involved in the widespread maternal endothelial dysfunction and result in hypertension, proteinuria, and other systemic manifestations of preeclampsia. ${ }^{41,42}$ In addition, VEGF-targeting therapies used in primary and metastatic carcinomas, as well as several other diseases 
disrupt the glomerular endothelium and result in hypertension, proteinuria, and thrombotic microangiopathy. ${ }^{40,43}$ In mice models, loss of VEGF function within the glomeruli leads to the loss of healthy fenestrated phenotype of endothelial cells and promotes the development of microvascular injury and thrombotic microangiopathy. ${ }^{44}$ However, in our present study, although the injected anti-VEGF antibody reacted with glomerular capillary walls, administration of anti-VEGF antibody for 7 days did not have any adverse effects on glomerular morphology, in particular, on the normal endothelial-cell morphology including fenestration, as well as glomerular pathology including thrombotic microangiopathy. We believe that the lack of effects of antiVEGF antibody on endothelial and glomerular pathology in the present study was probably related to the dose used, and its effect on endothelial injury and the extent of reduced VEGF activity. Clinically, the most common renal toxicities of VEGF antagonists are manageable; hypertension and proteinuria commonly regress after drug withdrawal. ${ }^{45}$ In this regard, a dose-dependent increase in risk of proteinuria and hypertension has been reported in patients with antiVEGF antibody-treated cancer. ${ }^{46,47}$

In summary, the present study on experimental immunemediated GN with destruction of the glomerular capillary network indicates that impairment of the capillary repair process in glomerular damage is associated with prolongation of glomerular inflammation, and subsequent development of glomerular sclerosis and proteinuria. Glomerular capillary repair has important roles in the recovery from glomerular damage and the resolution of proliferative GN.

\section{ACKNOWLEDGEMENT}

We thank Ms Naomi Kuwahara and Kyoko Wakamatsu for expert technical assistance.

\section{DISCLOSURE/CONFLICT OF INTEREST}

The authors declare no conflict of interest.

1. Ballerman BJ. Endothelial responses to immune injury. In: Neilson EG and Couser WG (eds) Immunologic Renal Diseases. Lippincott-Raven Publishers: Philadelphia, PA, 1997, pp 627-654.

2. Yamanaka N, Shimizu A. Role of glomerular endothelial damage in progressive renal disease. Kidney Blood Press Res 1999;22:13-20.

3. Ballerman BJ. Contribution of the endothelium to the glomerular permselectivity barrier in health and disease. Nephron Physiol 2007;106:19-25.

4. Kang DH, Johnson RJ. Vascular endothelial growth factor: a new player in the pathogenesis of renal fibrosis. Curr Opin Nephrol Hypertens 2003;12:43-49.

5. Stillman IE, Karumanchi SA. The glomerular injury of preeclampsia. J Am Soc Nephrol 2007;18:2281-2284.

6. Kitamura $H$, Sugisaki $Y$, Yamanaka $N$. Endothelial regeneration during the repair process following Habu-snake venom induced glomerular injury. Virchows Arch 1995;427:195-204.

7. Ostendorf T, Kunter U, Eitner F, et al. VEGF(165) mediates glomerular endothelial repair. J Clin Invest 1999;104:913-923.

8. Masuda Y, Shimizu A, Mori T, et al. Vascular endothelial growth factor enhances glomerular capillary repair and accelerates resolution of experimentally induced glomerulonephritis. Am J Pathol 2001;159: 599-608.
9. Shimizu A, Masuda Y, Mori T, et al. Vascular endothelial growth factor 165 resolves glomerular inflammation and accelerates glomerular capillary repair in rat anti-glomerular basement membrane glomerulonephritis. J Am Soc Nephrol 2004;15:2655-2665.

10. Kim YG, Suga S, Kang DH, et al. Vascular endothelial growth factor accelerates renal recovery in experimental thrombotic microangiopathy. Kidney Int 2000;58:2390-2399.

11. Iruela-Arispe L, Gordon K, Hugo C, et al. Participation of glomerular endothelial cells in the capillary repair of glomerulonephritis. Am J Pathol 1995;147:1715-1727.

12. Shimizu A, Masuda $\mathrm{Y}$, Kitamura $\mathrm{H}$, et al. Recovery of damaged glomerular capillary network with endothelial cell apoptosis in experimental proliferative glomerulonephritis. Nephron 1998;79:206-214.

13. Shimizu A, Masuda $Y$, Kitamura $\mathrm{H}$, et al. Complement-mediated killing of mesangial cells in experimental glomerulonephritis: cell death by a combination of apoptosis and necrosis. Nephron 2000;86:152-160.

14. Ferrara N. Vascular endothelial growth factor: molecular and biological aspects. Curr Top Microbiol Immunol 1999;237:1-30.

15. Klanke $B$, Simon $M$, Röckl W, et al. Effects of vascular endothelial growth factor (VEGF)/vascular permeability factor (VPF) on haemodynamics and permselectivity of the isolated perfused rat kidney. Nephrol Dial Transplant 1998;13:875-885.

16. Schrjvers BF, Flyvbjerg A, Vriese AD. The role of vascular endothelial growth factor (VEGF) in renal pathophysiology. Kidney Int 2004;65: 2003-2017.

17. Ostendorf T, De Vriese AS, Floege J. Renal side effects of anti-VEGF therapy in man: a new test system. Nephrol Dial Transplant 2007;22: $2778-2780$.

18. Simó R, Hernández C. Intravitreous anti-VEGF for diabetic retinopathy: hopes and fears for a new therapeutic strategy. Diabetologia 2008;51: 1574-1580.

19. Ferrara N, Hillan KJ, Novotny W. Bevacizumab (avastin) a humanized anti-VEGF monoclonal antibody for cancer therapy. Biochem Biophys Res Commun 2005;333:328-335.

20. van Wijingaarden $\mathrm{P}$, Qureshi $\mathrm{SH}$. Inhibitions vascular endothelial growth factor (VEGF) in the management of neovascular age-related macular degeneration: a review of current practice. Clin Exp Optom 2008;91:427-437.

21. Rini Bl. Vascular endothelial growth factor-targeted therapy in renal cell carcinoma: current status and future directions. Clin Cancer Res 2007;13:1098-1106.

22. Eremina V, Jefferson A, Ko walewska J, et al. VEGF inhibition and renal thrombotic microangiopathy. N Engl J Med 2008;358:1129-1135.

23. Kapiteijn E, Brand A, Kroep J, et al. Sunitinib induced hypertension, thrombotic microangiopathy and reversible posterior leukencephalopathy syndrome. Ann Oncol 2007;18:1745-1747.

24. Stokes MB, Erazo MC, D'Agati VD. Glomerular disease related to anti-VEGF therapy. Kidney Int 2008;74:1487-1491.

25. Mastui $\mathrm{Y}$, Mitsuyama K, Tomiyama N, et al. Efficacy of vascular endothelial growth factor in the treatment of experimental gastric injury. Digestion 2002;66:99-105.

26. Kondo $S$, Asano $M$, Suzuki $H$. Significance of vascular endothelial growth factor/vascular permeability factor for solid tumor growth and its inhibition by the antibody. Biochem Biophys Res Commun 1993;194:1234-1241.

27. Nangaku M, Pippin J, Richardson CA, et al. Beneficial effects of systemic immunoglobulin in experimental membranous nephropathy. Kidney Int 1996;50:2054-2062.

28. Jefferson JA, Suga SI, Kim YG, et al. Intravenous immunoglobulin protects against experimental thrombotic microangiopathy. Kidney Int 2001;60:1018-1025.

29. Horvat R, Palade GE. Thrombomodulin and thrombin localization on the vasculature endothelium: their internalization and transcytosis by plasmalemmal vesicles. Eur J Cell Biol 1993;61:299-313.

30. Nagashima M, Yoshino S, Ishiwata T, et al. Role of vascular endothelial growth factor in angiogenesis of rheumatoid arthritis. J Rheumatol 1995;22:1624-1630.

31. Floege J, Ostendorf $\mathrm{T}$, Janssen $\mathrm{U}$, et al. Novel approach to specific growth factor inhibition in vivo: antagonism of platelet-derived growth factor in glomerulonephritis by aptamers. Am J Pathol 1999;154: 169-179.

32. Hugo C, Pichler R, Gordon K, et al. The cytoskeletal linking proteins, moesin and radixin, are upregulated by platelet-derived growth factor, 
but not basic fibroblast growth factor in experimental mesangial proliferative glomerulonephritis. J Clin Invest 1996;97:2499-2508.

33. Modelli de Andrade LG, Viero RM, Carvalho MF. Role of peritubular capillaries and vascular endothelial growth factor in chronic allograft nephropathy. Transplant Proc 2009;41:3720-3725.

34. Choi YJ, Chakraborty S, Nguyen V, et al. Peritubular capillary loss is associated with chronic tubulointerstitial injury in human kidney: altered expression of vascular endothelial growth factor. Hum Pathol 2000;31:1491-1497.

35. Ohashi R, Kitamura H, Yamanaka N. Peritubular capillary injury during the progression of experimental glomerulonephritis in rats. J Am Soc Nephrol 2001;11:47-56.

36. Kang DH, Joly AH, Oh SW, et al. Impaired angiogenesis in the remnant kidney model: I potential role of vascular endothelial growth factor and thrombospondin-1. J Am Soc Nephrol 2001;12:1434-1447.

37. Ohashi R, Shimizu A, Masuda Y, et al. Peritubular capillary regression during the progression of experimental obstructive nephropathy. J Am Soc Nephrl 2002;13:1795-1805.

38. Kang $\mathrm{DH}$, Hughes J, Mazzali $M$, et al. Impaired angiogenesis in the remnant kidney model: II. Vascular endothelial growth factor administration reduces renal fibrosis and stabilizes renal function. J Am Soc Nephrol 2001;12:1448-1457.

39. Konda $R$, Sato $H$, Sakai $K$, et al. Expression of platelet-derived endothelial cell growth factor and its potential role in up-regulation of angiogenesis in scarred kidneys secondary to urinary tract diseases. Am J Pathol 1999;155:1587-1597.
40. Eremina V, Baelde HJ, Quaggin AE. Role of the VEGF-A signaling pathway in the glomerulus: evidence for crosstalk between components of the glomerular filtration barrier. Nephron Physiol 2007;106:32-37.

41. Maynard SE, Min JY, Mechan J, et al. Excess placental soluble fms-like tyrosine kinase 1(sFlt1) may contribute to endothelial dysfunction, hypertension, and proteinuria in preeclampsia. J Clin Invest 2003;111: 649-658.

42. Sugimoto $H$, Hamano $Y$, Charytan D, et al. Neutralization of circulating vascular endothelial growth factor (VEGF) by anti-VEGF antibodies and soluble VEGF receptor 1 (sFlt-1) induces proteinuria. J Bio Chem 2003;278:12605-12608.

43. De Vriese AS, Tilton RG, Elger $M$, et al. Antibodies against vascular endothelial growth factor improve early renal dysfunction in experimental diabetes. J Am Soc Nephrol 2001;12:993-1000.

44. Eremina V, Cui S, Gerber $\mathrm{H}$, et al. Vascular endothelial growth factor A signaling in the podocyte-endothelial compartment is required for mesangial cell migration and survival. J Am Soc Nephrol 2006;17: 724-735.

45. Launay-Vacher V, Deray G. Hypertension and proteinuria: a class-effect of antiangiogenic therapies. Anticancer Drugs 2009;20:81-82.

46. Zhu X, Wu S, Dahut WL, Parikh CR. Risks of proteinuria and hypertension with bevacizumab, an antibody against vascular endothelial growth factor: systematic review and meta-analysis. Am J Kidney Dis 2007;49:186-193.

47. Izzedine $\mathrm{H}$, Rixe $\mathrm{O}$, Billemont $\mathrm{B}$, et al. Angiogenesis inhibitor therapies: focus on kidney toxicity and hypertension. Am J Kidney Dis 2007;50: 203-218. 